\title{
Ricardo Parellada: El orgullo ¿vicio o virtud? Madrid, Editorial Síntesis, 2019, 332 pp.
}

\author{
Sonia E. Rodríguez \\ UNED \\ soniaerodriguez@fsof.uned.es
}

Casi coincidiendo con el final de año, llega hasta nosotros una curiosa novedad editorial, El orgullo ¿vicio o virtud?, escrito por Ricardo Parellada, Profesor Titular de la Facultad de Filosofía de la Universidad Complutense de Madrid, que la Editorial Síntesis ha tenido a bien publicar en la serie "Emociones, afectos y sentimientos". Tal vez esta sea la primera curiosidad, la inclusión dentro del ámbito general de filosofía de una serie específica dedicada al análisis filosófico de sentimientos. Cualquier despistado que se encontrase con este título sin tener referencias previas podría equivocarse ante la naturaleza del ensayo que hoy tengo el gusto de presentar. Pero todavía más curiosa resulta la belleza magistral con la que se aborda el análisis del sentimiento de orgullo, conjugando a la perfección una doble aproximación histórico-hermenéutica y filosófico-fenomenológica. Un rápido vistazo sobre el índice del libro refleja de forma clara el objetivo y los intereses del autor: reconstruir la historia del orgullo y examinar su relevancia en el mundo contemporáneo. Así, a un primer capítulo introductorio, que expone la dualidad del orgullo, le siguen dos partes claramente diferenciadas, «Historia del orgullo» y «Filosofía del orgullo». Y, si bien el ensayo cuenta con una tercera parte, «El futuro del orgullo», que recoge un último capítulo a modo de epílogo; la razón de publicar esta reseña en Investigaciones fenomenológicas 
se encuentra en el penúltimo capítulo, "Fenomenología del orgullo", con el que se cierra y, a mí parecer, culmina orgullosamente el análisis filosófico.

La dualidad del orgullo expuesta en el primer capítulo es el eje vertebrador de la investigación. Esta dualidad puede apreciarse en el lenguaje ordinario con la diferencia entre estar o sentirse orgulloso y ser orgulloso. En el primer caso, el orgullo es un sentimiento positivo vinculado a la propia excelencia; en el segundo caso, el orgullo es una seña o marca de carácter negativa que conlleva una actitud de superioridad o desprecio y que las más de las veces sería identificada como "soberbia". He aquí la dualidad y ambivalencia del orgullo. En este primer capítulo, Parellada también ofrece el estado de la cuestión, reseñando cuatro monografías que desde diferentes perspectivas han abordado la investigación en torno al orgullo. Pese a los diferentes enfoques, estas investigaciones coinciden en dos puntos fundamentales: todas señalan la dualidad del orgullo y todas confieren gran importancia a la historia del sentimiento con el fin de alcanzar la comprensión actual. El libro que hoy nos ocupa lugar ofrece una perspectiva complementaria a estas investigaciones y cuenta con el mérito no sólo de completar parte de la historia del orgullo, sino también de ofrecer lúcidos análisis filosóficos que culminarán con la propuesta ensayística de Parellada de una fenomenología del orgullo. En lo que sigue, esbozaremos someramente un mapa por los principales puntos de la investigación con el fin de presentar y mostrar la peculiaridad del análisis fenomenológico.

La primera parte, «Historia del orgullo», rastrea tanto las fuentes filosóficoliterarias de la Grecia clásica como las fuentes filosófico-teológicas de la religión judeocristiana con el mismo objetivo: reconstruir la historia, las variaciones y matizaciones que desde la antigüedad confluyen y posibilitan nuestra actual comprensión del orgullo. Ya en la Grecia clásica nos encontramos con una amplia variedad de objetos que pueden motivar nuestro sentimiento de orgullo. En un primer momento, Grecia se revela como modelo de aristocracia y democracia. La aristocracia guerrera pone de manifiesto la conciencia de excelencia de los héroes homéricos, un tipo de orgullo compartido por todas las aristocracias antiguas y que en los juegos olímpicos adquirirá una dimensión deportiva y corporativa. Pero el orgullo de la aristocracia guerrera cede el paso al orgullo democrático de los políticos que podemos encontrar hermosamente ilustrado tanto en la oración fúnebre de Pericles como en el mito de Prometeo. 
En un segundo momento, la aristocracia de sangre o del dinero será desplazada por la aristocracia intelectual con la que se fragua el orgullo de los filósofos. Platón, al tiempo que critica la democracia, exalta la educación filosófica y el nuevo modelo aristocrático de la excelencia que adquiere una doble dimensión, intelectual y moral. No es de extrañar que su filosofía desemboque finalmente en la propuesta del filósofo-rey como gobernante ideal de la polis. Por su parte, Aristóteles considera que la excelencia sólo puede hallar su perfección en la determinación anímica del magnánimo, aquel consciente de su propia excelencia, de la grandeza del alma; aquel que domina las virtudes éticas y puede dedicarse al aprendizaje de las virtudes dianoéticas. La doctrina aristotélica del justo medio determina la desmesura como ultraje, insensatez, insolencia... variantes estas del orgullo feo que se encuentran alumbradas en la húbris griega. Por último, al orgullo aristócrata de los héroes homéricos, al orgullo democrático de los políticos y al orgullo intelectual de los filósofos, cabe añadir un cuarto tipo de orgullo resaltado por Hesíodo: el orgullo laborioso de los campesinos, un orgullo fundamentado en la excelencia del trabajo.

Este breve recorrido por la Grecia clásica ilumina la pluralidad original de objetos que todavía hoy en día pueden despertar nuestro sentimiento de orgullo. Pero es necesario reconstruir las fuentes teológicas para comprender las connotaciones religiones que también impregnan nuestra actual comprensión del orgullo. Si la literatura y la filosofía griegas nos facilita enfatizar el orgullo bonito, la reconstrucción judeocristiana nos permite poner el acento en el orgullo feo, en el pecado de soberbia en que incurrieron tanto ángeles como humanos. La raíz del mal, en ambos casos, es la soberbia, el querer ser como Dios. El ángel caído quiso ser como Dios (por semejanza en el poder) y se convierte en demonio por su insumisión. También Eva quiso ser como Dios (en este caso, por semejanza en el saber) y provoca la caída de la humanidad. Pero, mientras que el pecado del ángel fue un pecado espiritual; el de Eva fue moral. Apoyándose en esta interpretación, Tomás de Aquino diferencia entre la soberbia espiritual y la soberbia moral, para poner de relieve la gravedad de la primera sobre la segunda. Para el de Aquino, el pecado general es compartido por ángeles y humanos y consiste en el apartarse de Dios, en la insumisión. Esta es la soberbia espiritual. En cambio, el pecado especial tiene carácter moral, es exclusivo del ser humano y consiste en un "apetito desordenado de la propia excelencia". 
A la soberbia espiritual del ángel y al orgullo intelectual de los seres humanos, debemos sumar las relaciones de poder y justicia. La historia del pueblo de Israel está determinada por una dialéctica de soberbia y humildad que permite vincular y entrelazar los dos grandes pilares del Antiguo Testamento: la piedad, entendida como sumisión espiritual, y la exigencia de justicia con huérfanos, viudas y extranjeros. Por último, tras haber bosquejado las fuentes filosófico-literarias de la Grecia clásica y las fuentes filosófico-teológicas del judeocristianismo, Parellada avanza en el tiempo para cerrar su reconstrucción histórica con un original análisis de Fausto. Para el autor, la curiosidad y el afán de saber de Fausto no son un ejemplo más de desmesura y soberbia, sino que se aúna con la impiedad como insumisión; es decir, en la figura de Fausto se articulan el pecado de Eva y el pecado de Satán. Finaliza de este modo una reconstrucción histórica que, pese a su carácter fragmentario, ha alumbrado los matices que como sentimiento y como marca de carácter el orgullo va adquiriendo en su devenir.

La segunda parte, «Filosofía del orgullo», se aproxima al sentimiento desde una vertiente más analítica con el fin de resolver dos cuestiones fundamentales: la naturaleza del orgullo y su relación con otros fenómenos psíquicos. Estos análisis ponen de manifiesto el paso de la psicología medieval a la filosofía moderna. La nueva filosofía rechaza las facultades del alma de la antropología medieval y abre la comprensión a las denominadas "pasiones del alma". Para Descartes, el orgullo es una pasión, pero también una disposición o hábito. El juicio y la valoración que fundamenta la pasión del orgullo es la "buena opinión" sobre uno mismo; cuando esta es razonable cristaliza en hábitos positivos y da lugar a la virtud de la autoestima o magnanimidad; cuando no es razonable cristaliza en hábitos negativos y da lugar al vicio de la soberbia. Por su parte, para Hume el orgullo es un sentimiento que admite un sentido positivo y otro negativo. El orgullo noble (sentido positivo) radica en la afirmación del propio ser y de la propia dignidad. Mientras que para Spinoza el orgullo es contento y diferencia entre la arrogancia del soberbio y el contento de sí del sabio.

Pero esta comprensión que desde la filosofía moderna se va fraguando recibe un fuerte envite con el filósofo del martillo. Para Nietzsche, la valoración de la excelencia guerrera es propia en todas las aristocracias antiguas y el judeocristianismo es el responsable de la transmutación de los valores. El desplazamiento de la moral aristócrata a la moral de los plebeyos es, para Nietzsche, fruto del resentimiento. En este punto, Parellada realizar un análisis del mecanismo del 
resentimiento distinguiendo dos pasos: en primer lugar, el sujeto estima algo que no es capaz de alcanzar y, en consecuencia, decide que no merece la pena; $y$, en segundo lugar, pese al intento de cambiar su valoración inicial, no es capaz de desprenderse de ella y surge la impotencia y el rencor. En función de este análisis, la humildad cristiana surge de la impotencia y el rencor ante el orgullo aristócrata. Sin embargo, frente a la perspectiva nietzscheana de la humildad como impotencia, el autor se anima a dibujar una nueva perspectiva de la humildad cristiana como fraternidad cuyo máximo esplendor será la igualdad.

Ciertamente, la historia contemporánea del orgullo pivota en torno a la idea de la igualdad. En este punto, también la filosofía española aporta lúcidos análisis a esta investigación. Así el poeta-filósofo que es Machado dirige la atención a lo que nos une y a la dimensión religiosa del orgullo de la igualdad suma una dimensión patriótica, la grandeza de lo que somos y de los que compartimos. Por su parte, el filósofo-poeta que es Unamuno se escandaliza ante el hecho de que su ansia de inmortalidad sea tildada de soberbia, y vuelca su orgullo bueno en una versión moderna del orgullo del trabajo y la laboriosidad. Y, por supuesto, Ortega también tiene un hueco en la investigación sobre el orgullo y la soberbia contemporáneos. La soberbia espiritual o insumisión reaparece en forma mundana en la rebelión de las masas. Surge, así, lo que Parellada denomina orgullomasa, una afirmación de nivelación, vulgaridad y odio a los superiores.

Pero igual que el desarrollo moderno de la política de la identidad se ve abocado a la política de la diferencia, el orgullo de la identidad debe abrir paso al orgullo de la diferencia, uno de los nuevos modos modernos de orgullo. El autor recurre aquí a dos ejemplos paradigmáticos: el orgullo negro y el orgullo LGBTI. El primero es la afirmación de una identidad racial y supone la autoafirmación del valor propio. El segundo es un modo de resistencia individual y colectiva frente a la opresión y la exclusión social. Curiosamente, ambos, aunque quizá de forma más significativa el segundo, se mueven del orgullo de la diferencia al orgullo de pertenencia a un colectivo. Este último, el orgullo colectivo, pese a ser una forma moderna de orgullo admite distinciones similares a las formas individuales de orgullo: apropiado /inapropiado, auténtico/desmesurado. Entre otras formas de orgullo colectivo, el autor analiza el derivado del deporte, de las profesiones, del patriotismo e, incluso, de la actual vida política española.

Y llegamos así, en nuestro apresurado y apretado recorrido, al análisis fenomenológico del orgullo. En este punto, Parellada busca reconducir la pluralidad 
de orgullos a una estructura fundamental que revele las notas esenciales del sentimiento para, en un camino de ida y vuelta, reconstruir y dar cuenta de las distintas variaciones históricas y conceptuales. Su fórmula pasa por la identificación de cinco elementos en la estructura del orgullo: el yo (sujeto) que siente (relación) su propia (objeto material) excelencia (objeto formal) de forma ordenada/desordenada (modo). Cada uno de estos elementos - sujeto, relación, objeto material, objeto formal y modo- admite variaciones y la conjugación de estas variaciones permite analizar la riqueza y complejidad del fenómeno. En primer lugar, la reconstrucción histórica y los análisis filosóficos previos nos han permitido identificar al menos cuatro variaciones en la relación del sujeto y el objeto material: como apetito (Tomás de Aquino), como opinión (Descartes), como sentimiento (Spinoza/Hume), como estimación (Ortega). En segundo lugar, podemos atender de modo simultáneo a las variaciones del sujeto y del objeto material. El sujeto (yo) y el objeto material (lo propio) coinciden en el orgullo. La variedad de objetos materiales es innumerable, pero todos dependen del individuo, de lo que uno es o quiere ser. Pero, en tercer lugar, lo realmente interesante de las variaciones del objeto material es que ponen de manifiesto lo que para el autor es una doble intencionalidad que se dirige, en un primer momento, al objeto material original (uno) y, en segundo momento, a la variación de la cualidad (peinado, inteligencia, etc.). En cuarto lugar, los análisis previos también nos han permitido identificar diferentes variaciones eidéticas del objeto formal del orgullo. La excelencia podía venir determinada por el mérito y el esfuerzo, por la comparación o por la nivelación mediocre. Y, por supuesto, en quinto y último lugar, las variaciones del modo más básicas en función del orden/desorden, mesura/desmesura nos devuelven a la dualidad del orgullo con la que iniciamos. Estas son, grosso modo, las líneas generales de esta original fenomenología del orgullo iniciada por Ricardo Parellada, un ejercicio práctico que, sin lugar a duda, deberá ser tenido en cuenta por todos aquellos interesados en la estimulante fenomenología de los sentimientos.

Por falta de espacio y no de ganas, dejo al lector el placer de descubrir otras mil historias, anécdotas, paralelismos y comparaciones, así como la digresión final acerca del futuro del orgullo, el orgullo posthumano o potsorgullo. 